\title{
O PROCESSO DE INCLUSÃO ENQUANTO POLÍTICA PARA A EDUCAÇÃO PROFISSIONAL BRASILEIRA
}

THE PROCESS OF INCLUSION AS A POLICY FOR THE BRAZILIAN PROFESSIONAL EDUCATION

EL PROCESO DE INCLUSIÓN COMO UNA POLÍTICA PARA LA EDUCACIÓN PROFESIONAL BRASILEÑA

\author{
GATTERMANN, Beatris 1 \\ POSSA, Leandra Boer²
}

\begin{abstract}
RESUMO
Este trabalho problematiza e contextualiza os discursos que movimentam a reforma da educação profissional no Brasil, as políticas de inclusão de jovens na educação profissional de nível médio e as estratégicas de permanência e aprendizagem que estão produzindo outros modos de dizer sobre o estudante em situação de não aprendizagem. $\mathrm{O}$ artigo toma como referência o espaço educativo de um Instituto Federal de Educação do Estado do Rio Grande do Sul e como grade de análise as práticas de governamento, a noção de norma e de curva de normalidade, presentes nos estudos de Michel Foucault e de alguns de seus estudiosos.
\end{abstract}

Palavras-chave: Inclusão. Governamentalidade. Política Educacional.

\section{ABSTRACT}

This work problematizes and contextualizes the speech that mobilize the reform of professional education in Brazil, the policies for the inclusion of young people in professional education and perpetual learning strategies that are producing other ways of saying about the student in a non-learning situation. The article takes as a reference the educational space of a Federal Institute of Education of the state of Rio Grande do Sul in Brazil, concentrating on the analysis of the governance practices, the notion of norm and the normality curve, present in the studies of Michel Foucault and some of his scholars.

Keywords: Inclusion. Governmentality. Educational policy.

\section{RESUMEN}

Este trabajo problematiza y contextualiza los discursos que moviliza la reforma de la educación profesional en Brasil, las políticas de inclusión de jóvenes en la educación profesional de nivel medio y las estrategias de permanencia y aprendizaje que están produciendo otros modos de decir sobre el estudiante en situación de no aprendizaje. El artículo toma como referencia el espacio educativo de un Instituto Federal de Educación del Estado de Rio Grande do Sul concentrándose en los análisis de las practicas de gobernamento, la noción de norma y de la curva de normalidad, presentes en los estudios de Michel Foucault y de algunos de sus estudiosos.

Palabras clave: Inclusión. Gobernabilidad. Politica educativa.

\footnotetext{
1 Universidade Federal de Santa Maria - UFSM - Santa Maria - Rio Grande do Sul - Brasil.

2 Universidade Federal de Santa Maria - UFSM - Santa Maria - Rio Grande do Sul - Brasil.
} 


\section{INTRODUÇÃO}

O presente trabalho foi produzido com objetivo de contextualizar problematizações realizadas na Dissertação de Mestrado intitulada Inclusão no IF Farroupilha Campus Santo Augusto: Conjunto de Práticas Políticas que tem Produzido Sujeitos, apresentado no Programa de Pós-graduação em Educação da Universidade Federal de Santa Maria (UFSM) no ano de 2017. Esta pesquisa objetivou apresentar uma análise dos discursos que movimentam políticas de inclusão na educação profissional, implementadas a partir da criação dos Institutos Federais de Educação (IFs) no Brasil e do Instituto Federal Farroupilha (IFFar), e, também, elementos para identificar e compreender como as estratégias de permanência e de aprendizagem colocadas em ação a partir dessas políticas de inclusão, no que se refere à produção de outros modos para se dizer do estudante em situação de não aprendizagem. Portanto, a intenção deste artigo é também prestar contas da pesquisa desenvolvida no Programa de Pós-Graduação em Educação, da Universidade Federal de Santa Maria. Ao prestar contas, colocar os resultados vislumbrados à disposição da comunidade acadêmica.

O desenvolvimento da pesquisa se deu a partir de diferentes materiais e com diferentes movimentos. Para construir um cenário utilizou-se alguns documentos internacionais que orientam políticas educacionais nacionais de criação dos Institutos Federais de Educação (IFs), em que a inclusão pode ser lida pela noção fortemente embasada em uma perspectiva da aprendizagem. Um segundo movimento para completar o cenário foi construído para olhar os documentos nacionais que servem de base para a criação dos IFs, buscando mostrar o investimento nessas instituições para a inclusão de jovens na Educação Profissional. E, por fim, a analise mais detalhada de documentos do Instituto Federal Farroupilha (IFFar) e em específico de programas, projetos, atas e registros do IFFar Campus Santo Augusto, para entender as estratégicas de permanência e aprendizagem que estão produzindo outros modos de dizer sobre o estudante em situação de não aprendizagem e a visualização de como essa produção tem movimentado a constituição dessa instituição.

Sobre esse recorte analítico nos documentos em um instituto federal, o IFFar - Campus Santo Augusto, é importante considerar que a investigação é tomada pela noção de implicação em que o investigador, a partir de seu lugar de atuação (tendo em vista a atividade profissional da pesquisadora nesse lugar), pode contribuir com as mudanças possíveis. Ou seja, um pesquisador que organiza pela pesquisa, saberes para produzir e conhecer melhor as práticas de uma das instituições criadas a partir da Lei de reforma da Rede Federal de Educação Profissional de 2008, e, que vem se constituindo pela processualidade já que ao mesmo tempo que se produz enquanto instituição, também produz/forma profissionais. A nosso ver, é o processo de investigação das práticas em uma instituição em movimento de consolidação que qualifica o trabalho em uma instituição ainda imatura em termos de tempo.

Retomando os documentos, a análise produzida teve uma inspiração nos estudos foucaultianos, em que, foi possível emergir conceitos-ferramentas que potencialmente auxiliam, estes foram: a governamentalidade, a noção de norma e a noção de curva de normalidade.

Ao operar com as ferramentas metodológicas, o estudo se constitui em três movimentos: o primeiro, foi a análise do conjunto de documentos internacionais buscando identificar como a adoção da inclusão, como forma de determinação das condições para educação na atualidade, pode ser 
explicitada na ordem da governamentalidade neoliberal criando algumas condições de possibilidade para a reforma da educação profissional e criação dos IFs no Brasil; o segundo, foi a análise dos discursos presentes nos documentos do IFFar, os quais, operam a inclusão pela captura dos jovens para a educação profissional, verificando a emergência da aprendizagem como discurso útil para gestão da aprendizagem e permanência do estudante na educação profissional; por fim, a análise de algumas práticas discursivas e táticas que tomam a aprendizagem como estratégia de inclusão, atualizando, no presente, modos de relação (in)exclusão e de produção de sujeitos em situação de não aprendizagem. No parágrafo acima já está dito dos referenciais a governamentalidade, a noção de norma e a noção de curva de normalidade. Esses serão conceituados ao longo do texto não de forma direta, mas em operação analítica.

\section{A INCLUSÃO, A GOVERNAMENTALIDADE NEOLIBERAL E AS PERSPECTIVAS PARA A REFORMA DA EDUCAÇÃO PROFISSIONAL}

As agendas políticas internacionais constituem a síntese de uma ordem política e econômica na governamentalidade neoliberal. Estas, oferecem as condições de possibilidade para definição das políticas educacionais nacionais na perspectiva inclusiva, e, para a reforma da educação profissional no Brasil. Este tensionaento foi possível empreender tomando os seguintes documentos internacionais: Declaração de Educação para Todos (1990); Estratégias do Banco Interamericano para Desenvolvimento do Brasil 2000 - 2003 (2000); Agenda 2020 - BM (2011) e Declaração de Incheon Educação 2030 - UNESCO. A possibilidade de olhar para esses documentos é para construir um cenário de discussão da educação profissional no Brasil, tomando como base o elemento tão profanado da aprendizagem.

O impacto desses documentos, no Brasil, começa na década de 1990, no momento da redemocratização do país e com a maior participação como Estado Membro dos organismos internacionais. Este momento corresponde ao período em que o Brasil efetivamente traz, para os problemas de Estado e da sociedade civil, a perspectiva neoliberal como racionalidade de governo e condução. Sobre isso, o estudo de Rech (2015) aponta a década de 1990 como um espaço de tempo em que "[...]a área educacional estava sendo pensada tendo como norte a nova racionalidade neoliberal - que se instalava no país" (p. 118). Acrescenta, ainda, que nesta nova racionalidade,

\footnotetext{
A racionalidade neoliberal permite que cada um funcione como uma empresa [...] Portanto, nada mais adequado para os neoliberais que ter a educação imersa neste pensamento, e ao mesmo tempo, compactuando com os princípios que visam ao jogo da livre concorrência. Nesse sentido, faz-se necessário entrar no jogo, ou seja, aproximar a escola do mundo do trabalho, na busca por resultados mais expressivos, mais lucrativos, e também na busca por sujeitos que invistam em si mesmos. (RECH, 2015, p. 119).
}

Juntamente com isso, Gouveia (2005) acentua em seus estudos que, a partir da década de 90 no Brasil, "[...] o neoliberalismo e as agências multilaterais passaram a orientar as políticas públicas, 
dentre elas as políticas educacionais" (p. 34). É nesse contexto de políticas neoliberais, referenciadas em discursos dos organismos internacionais, que, segundo esses estudos, a partir da década de 90, operam as reformas educacionais no Brasil, entre elas o da educação profissional.

Sob esse entendimento, torna-se perceptível a emergência do discurso inclusivo para os sistemas e instituições educativas; no entanto, a inclusão é um princípio que já circulava com outros nomes em décadas anteriores como pontua Mendes: "[...] os movimentos sociais pelos direitos humanos, intensificados basicamente na década de 1960, conscientizaram e sensibilizaram a sociedade sobre os prejuízos da segregação e da marginalização de indivíduos de grupos com status minoritários". (2006, p. 388).

O debate, portanto, da inclusão como princípio educacional, se constitui de uma captura pelo movimento político e pela racionalidade neoliberal, de lutas sociais que já circulavam com diferentes matizes conferindo-lhe valor de verdade. Isso nos leva a considerar que a inclusão aparece, em documentos de orientação dos organismos internacionais, com diferentes nomes, associada a outras palavras e produzindo sentido para tornar-se diretriz ou perspectiva para a política educacional brasileira. Isso é possível constatar no quadro 1, que sistematiza algumas recorrências em que a inclusão está presente:

\section{Quadro 1 - RECORRÊNCIAS DISCURSIVAS EM DOCUMENTOS INTERNACIONAIS}

\begin{tabular}{|c|c|c|c|}
\hline $1990^{3}$ & $2000-2003^{4}$ & $2011^{5}$ & $2015^{6}$ \\
\hline Indivíduo/todos & Todos/Competitividade & $\begin{array}{c}\text { Aprendizagem de } \\
\text { todos }\end{array}$ & Todos e por toda vida \\
\hline Aprendizagem & Desenvolvimento & Conhecimento & Aprendizagem \\
\hline
\end{tabular}

Fonte: GATTERMANN (2017, p. 70)

Observando o quadro produzido, e na imersão nos documentos selecionados para análise, é possível identificar o cenário para trazer a noção de aprendizagem que sustenta a inclusão e valida a expansão dos IFS. As recorrências enunciativas presentes nos documentos expressam que as reformas na educação no Brasil, sob efeito de discursos políticas internacionais, estão envoltas por duas referências: a inclusão e a aprendizagem. A noção de aprendizagem toma centralidade nas políticas educacionais de inclusão como elemento que coloca os indivíduos em processo de inclusão. Isso evoca a responsabilidade de aprendizagem como modo de estarem incluídos e manterem-se incluídos. Uma característica que implica investir em si, nas suas aprendizagens de maneira constante, um modo de ser e produzir-se sujeito, de manter-se aprendo ao longo da vida, condição sine qua non para se adequar, estar no mundo e ser incluído.

\footnotetext{
${ }^{3}$ Declaração de Educação para Todos (1990).

${ }^{4}$ Estratégias do Banco Interamericano para Desenvolvimento do Brasil 2000 - 2003 (2000).

${ }^{5}$ Agenda 2020 - BM (2011).

${ }^{6}$ Declaração de Incheon - Educação 2030 - UNESCO.
} 
Nesse contesxto, incluir e aprender correspondem a uma educação que institucionaliza a todos e, toma a instituição escolar como espaço que, na contemporaneidade, tem como atribuição investir e tornar necessário o desejo de aprender. Que seja capaz de capturar a todos para uma formação que vai se destinar a cada um, tomando como referência "[...] satisfazer suas necessidades básicas de aprendizagem" (UNESCO, 1990, p. 02). Como se elas fossem necessidades do indivíduo e, com isso, passassem a definir um tipo e um modo de ser do indivíduo no contexto social. Ou seja, necessidades básicas definem e dirigem um modo de ser do indivíduo, capturando-o no sentido de que façam dessas necessidades de aprendizagem suas próprias necessidades. São elas:

\begin{abstract}
os instrumentos essenciais para a aprendizagem (como a leitura e a escrita, a expressão oral, o cálculo, a solução de problemas), quanto os conteúdos básicos da aprendizagem (como conhecimentos, habilidades, valores e atitudes), necessários para que os seres humanos possam sobreviver, desenvolver plenamente suas potencialidades, viver e trabalhar com dignidade, participar plenamente do desenvolvimento, melhorar a qualidade de vida, tomar decisões fundamentadas e continuar aprendendo. (UNESCO, 1990, p. 02).
\end{abstract}

Cada momento histórico produz discursos que são praticados como verdades sobre as relações no mundo, e, também, como produção de sujeitos, de realidades culturais, sociais, econômicas e educacionais. Os tensionamentos realizados permitem identificar a aprendizagem com status de verdade, como estratégia de ordenamento das práticas educativas que operam no governamento de condutas de um tipo de sujeito que se nomeia como "aprendente", capaz de, modeladas as aprendizagens, governar a si e constituir-se responsável por produzir a si mesmo.

Assim, no jogo econômico neoliberal, a aprendizagem tem valor de investimento e de adequação do sujeito; e a instituição escolar passa a ser uma maquinaria com a incumbência de conduzir esse sujeito a aprender a aprender, para participar do jogo neoliberal que se apresenta como:

[...] «conducción de las conductas» [...] neoliberalismo como gubernamentalidad o mentalidad de gobierno centra el foco de atención en las formas de ejercer una «gubernamentalización de Estado (Lemke, 2001) o gubernamentalización de lo social» (Dean, 1999). [...] La gubernamentalidad neoliberal se sostiene como políticas de Estado que se fundamentan en dirigir la conducta de las conductas a través de estrategias de libertad que responsabilizan a los sujetos de sus aciertos y errores (Burchell, Gordon, \& Miller, 1991; Dean, 1999; Rose \& Miller, 1992). (SAURA, 2016, p. 15).

Nesse sentido, o neoliberalismo, sendo uma forma de governamentalidade que vem caracterizando um modo de vida contemporâneo, pode ser considerado como um conjunto de práticas que atua de maneira sutil na condução das condutas dos indivíduos e da população, que mobiliza estratégias de gestão das subjetividades, que fabrica um modo de vida, um tipo específico de sujeito que investe permanentemente em si mesmo.

Nessas formas de governamentalidade, as políticas globais e universalizantes dos organismos internacionais vêm dirigindo as reformas educativas no Brasil, no sentido, de que as políticas 
educativas sejam implantadas no sistema e nas instituições, nos processos formativos e de aprendizagem. Não é uma imposição, mas uma captura, uma criação de desejo e vontade, pois a educação é uma estratégia orientada para a liberdade e para a responsabilização dos sujeitos.

Não queremos esgotar qualquer definição sobre o neoliberalismo ou finalizar qualquer conclusão sobre a implicação da governamentalidade neoliberal nos processos de reformas nas políticas de educação profissional. O que objetivamos é mostrar com a ferramenta da governamentalidade, na análise dos documentos internacionais, a racionalidade neoliberal em curso na construção de discursos de inclusão e de aprendizagem, que circulam nas propostas e práticas educativas de um Instituto Federal de Educação, criado por essas reformas dos sistemas educativos.

Mais especificamente, mostrar que as reformas vêm produzindo um tipo de educação que atua como estratégia na produção de um modo de ser do sujeito aprendente, que precisa se profissionalizar adequadamente, pois a normativa de habilidades e competências passam a ser desejadas e nomeadas como necessidades do próprio sujeito que se responsabiliza por suas aprendizagens; ele passa a acreditar que ela é o que vai lhe constituir produtivo. Logo, uma governamentalidade como estratégia que opera sobre todos e cada um, num jogo implica

[...] o conjunto constituído pelas instituições, procedimentos, análises e reflexões, cálculos e táticas que permitem exercer essa forma bem específica, bem complexa de poder, que tem como alvo principal a população, como forma mais importante de saber, a economia política como instrumento técnico essencial, os dispositivos de segurança. (FOUCAULT, 2008, p. 143-144).

No contexto de uma governamentalidade neoliberal, numa conjuntura econômica globalizada, com a inovação tecnológica e a circulação cada vez maior da informação, é vital uma educação que capacite todos para competir no mercado. A qualificação profissional, portanto, é condição maior de um sujeito constituído de competências e habilidades para a aprendizagem continuada. Um sujeito que domine as noções básicas que lhe dão condições de: adaptar-se às mudanças de forma rápida, solucionar problemas, capacidades de iniciativa e decisão, bem como, que seja produtivo para esse mercado - é interesse desse investimento. Isso justifica as metas do BID para o Brasil:

[...] desenvolvimento e a expansão da educação primária, (graus 1 a 8), melhoria e expansão da educação média (graus 9 a 11), e reforma do ensino profissional (educação para o trabalho), [...] melhoramento da qualidade do ensino, especialmente do ensino médio como nível que prepara os alunos para enfrentar o mundo do trabalho. (BID, 2000, p. 25).

Nesse sentido, a expansão das escolas técnicas, reformadas como IFs, e da Rede Federal de Educação Profissional pode ser lida como cumprimento de metas de um projeto neoliberal orientado pelos organismos internacionais, o que se confirma com o fragmento do BID quando diz: "[...] expansão do sistema educativo concentrando esforços no ensino médio, com ênfase em medidas que favoreçam o acesso aos grupos menos favorecidos" (BID, 2000, p. 25). 
Essa meta é confirmada na ideia de ampliação do alcance das redes de captura para que nenhum jovem fique de fora, para que todos estejam incluídos, considerando-se a necessidade de as políticas educacionais no Brasil "[...] ampliar[em] os meios de, e o raio de ação da educação básica" (UNESCO, 1990, p. 05).

Um dos pontos que move as orientações dos organismos internacionais é a Educação para Todos. Este, parece ser o aspecto que orienta a elaboração das diretrizes para a educação no Brasil, como um princípio regulador que produz efeitos sobre a vida de todos, regrando a maneira como cada um deve agir, conduzir a sua vida e conduzindo a vida dos outros. Assim, a educação profissional aparece "[...] alinhada com as políticas de inclusão e com um projeto de nação" (BRASIL, 2010, p. 39), que propõe uma educação para todos.

Esses discursos, que dizem de investimentos no ensino médio, de reforma na educação profissional, de expansão do sistema educativo, de captura dos jovens para a última etapa da educação básica, tiveram como efeito a criação dos IFs no ano de 2008. De acordo com Art $7^{\circ}$ da Lei n 11.892 de 29 de dezembro de 2008, os IFs são instituições criadas para atender o objetivo de: "[...] ministrar educação profissional técnica de nível médio, prioritariamente na forma de cursos integrados, para os concluintes do ensino fundamental" (BRASIL, 2008). Essa rede de instituições, que tem como um de seus focos de atuação a formação de jovens através do ensino médio integrado à educação profissional, cria uma rede de investimento financeiro e de estratégias educativas no ensino médio, na preparação dos jovens para o mundo do trabalho.

Ainda no Art $7^{\circ}$ da Lei $n^{0} 11.892$ de 29 de dezembro de 2008, está definido que um dos objetivos dos IFs é "[...] estimular e apoiar processos educativos que levem à geração de trabalho e renda e à emancipação do cidadão na perspectiva do desenvolvimento socioeconômico local e regional" (BRASIL, 2008). Trata-se, assim, de um conjunto de instituições e estratégias operadas por saberes educativos para que o sujeito se torne produtivo de modo a estar se preparando, sob determinados critérios de produtividade econômica, para ser capaz de constituir-se capital humano.

\section{RESSONÂNCIAS DA POLÍTICA INCLUSIVA NA CRIAÇÃO DOS IFS E DO IFFAR E OS MODOS DE CAPTURA DOS JOVENS PARA EDUCAÇÃO PROFISSIONAL}

Num segundo movimento, a problematização se dá sobre os discursos de inclusão e aprendizagem presentes nos documentos nacionais de criação dos IFs e nos documentos institucionais do IFFar, ao tensionar como esses discursos atuam como modo de captura dos jovens para a educação profissional, tornando-se úteis para a implementação de estratégias de gestão pedagógica da aprendizagem do indivíduo, e, de permanência do estudante na educação profissional de nível médio.

Entre os documentos analisados, e, que conduzem as estratégias de inclusão no âmbito da Rede Federal e do IFFar, estão: Lei 11.892/2008 - Institui a Rede Federal de Educação Profissional e cria os IFs; Plano de Desenvolvimento Institucional 2014-2018 do Instituto Federal Farroupilha; Programa de Apoio Didático Pedagógico aos estudantes do IFFar, e PPCs dos Cursos Técnicos Integrados ao Ensino Médio do IFFar Campus Santo Augusto. 
Sem adentrar no detalhamento dos aspectos históricos da Rede Federal de Educação Profissional, mas para tensionar sobre as políticas que conduzem essas reformas, o gráfico a seguir apresenta o cenário da atuação da Rede Federal desde sua criação em 1909 até o ano de 2014:

Figura 1 - Cenário da Rede Federal de Educação Profissional

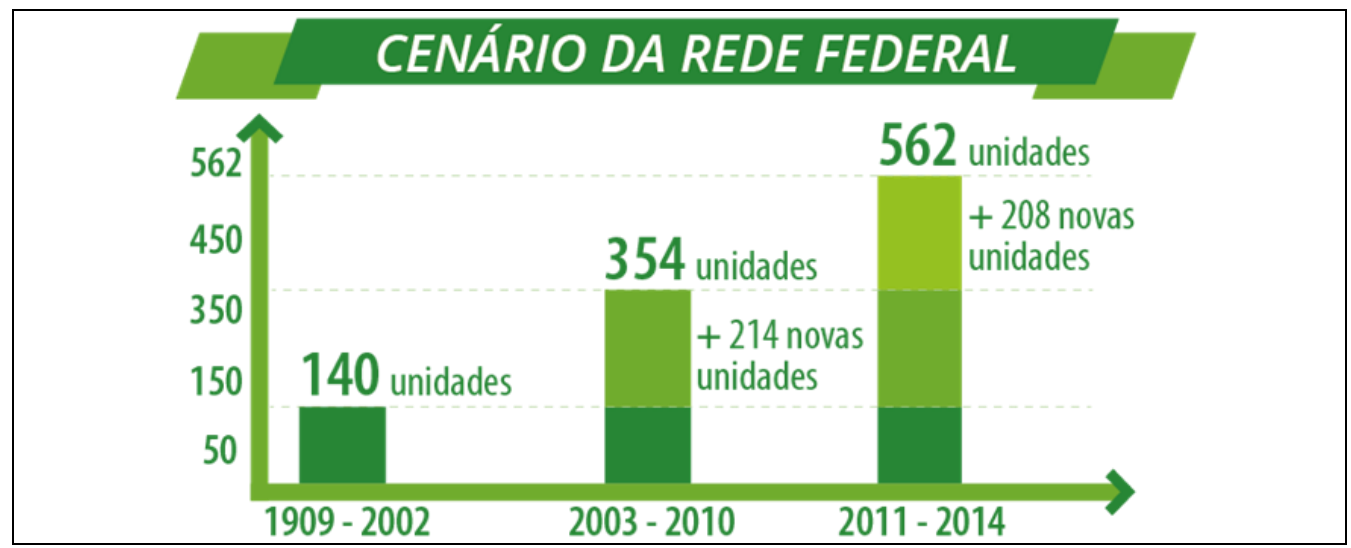

Fonte: MEC/SETEC, 2010.

Esse cenário mostra como as políticas educacionais no Brasil foram se constituindo, entre os anos de 2002 e 2014, nos governos de Luiz Inácio Lula da Silva e Dilma Rousseff, tendo em vista a prioridade dada para a expansão da educação profissional como projeto de inclusão social via educação. Os investimentos em educação profissional nesse período se multiplicaram, e, mudanças estruturais, organizacionais e pedagógicas foram sendo realizadas.

O Plano de Desenvolvimento da Educação 2007, toma os IFs como "[...] modelos de reorganização das instituições federais de educação profissional" e prevê que, "[...] de 2003 a 2010, serão autorizadas 214 novas unidades federais, ou seja, teremos realizado uma ampliação de $150 \%$ do parque federal de educação profissional e tecnológica em apenas oito anos" (BRASIL, 2007, p. 32).

Esse investimento, teve relação direta com análises e projeções realizadas pelos organismos internacionais para o Brasil, podendo aqui citar o Panorama Educativo: Indicadores da OCDE. Trata-se de um documento produzido em 2003 para "[...] vigiar mais de perto o seu desempenho" (OCDE, 2003, p. 2), isto é, os recursos gastos em Educação dos países membros. O documento aconselha o investimento em educação, considerando que: "[...] Na maioria dos países da OCDE, a taxa de participação das pessoas em idade ativa aumenta com o nível de formação" (p. 6).

Os documentos que tratam da reforma da educação profissional no Brasil apresentam-se alinhados com as orientações dos organismos internacionais. A inclusão de todos, e, a aprendizagem promulgada como modo de ser do sujeito no presente, passam a desempenhar papel fundante nas reformas da educação profissional, na criação dos IFs; e, nesse contexto de produção, o IFFar.

Os investimentos do Estado em políticas de educação profissional colocam-se como um modo de operar que condiciona a todos participar do jogo econômico, pondo em funcionamento "[...] uma das principais regras do jogo neoliberal: a inclusão de todos" (LOCKMANN, 2013, p. 33). E a ampliação da 
Rede Federal viabiliza essa captura de todos. Isso se confirma ao consultar a página da Secretaria de Educação Profissional em maio de 2016, em que os IFs se encontravam distribuídos em 568 cidades do Brasil e totalizavam 644 campi, ultrapassando o número de instituições previsto no PDE 2007.

É nesse contexto que o IFFar elabora documentos internos que conduzem a organização, bem como, a implantação das políticas inclusivas, e, a partir deles, as estratégias de inclusão e de captura de todos. O tensionamento dos documentos que dizem como a instituição pensa e pratica a inclusão em seus espaços educativos; e, que ao mesmo tempo elencam as estratégias para as políticas de educação profissional inclusiva desenvolvidas no IFFar, permite organiza-las em duas categorias: as estratégias de inclusão pelo acesso e as estratégias de permanência dos jovens na educação profissional do IFFar.

As estratégias de captura pelo acesso constituem-se em mecanismos de atração dos jovens para a educação profissional de nível médio. No tensionamento dos documentos constatou-se a presença de discursos que atravessam as políticas institucionais de acesso dos jovens à educação profissional, entre eles: campanhas dos processos seletivos para ingresso de jovens na educação profissional de nível médio, Programa Institucional de Ampliação do Acesso, bem como o edital e o manual do candidato do processo seletivo 2017. Esses documentos do IFFar movimentam estratégias para criar nos jovens o desejo de ingressar em um dos cursos técnicos integrados ao ensino médio, oportunizados através dos "[...] seus 10 (dez) Câmpus" (PDI 2014-2018, p. 205).

Os documentos evidenciaram que a noção de marketing está presente de modo muito intenso nessa perspectiva de captura, considerando que a captura se dá pelo convencimento, pela subjetivação do jovem para cursar educação profissional, constituindo-se, portanto, como um bom investimento em si.

O quadro 2 é resultado do perfil do estudante dos cursos técnicos integrados do IFFar Campus Santo Augusto do ano de 2015, no momento o Campus possui quatro cursos técnicos integrados: "[...] administração, agropecuária, alimentos e informática" (PDI 2014-2018, p. 138). Como podemos observar, o quadro 2 mostra alguns discursos que tem subjetivado os jovens para desejar cursar educação profissional no IFFar:

\section{Quadro 2 - MOTIVOS DE TER ESCOLHIDO UM CURSO TÉCNICO INTEGRADO NO IFFAR CAMPUS} SA

\begin{tabular}{|l|c|c|}
\hline Escolheu cursar educação profissional - técnico integrado & sim & não \\
\hline Para entrar na universidade & 116 & 199 \\
\hline Como preparação para o mundo do trabalho & 156 & 159 \\
\hline Pela qualificação dos professores & 122 & 193 \\
\hline Pelo ensino gratuito & 119 & 196 \\
\hline Pela imagem da instituição na comunidade & 69 & 246 \\
\hline Identificação com a área do curso & 110 & 205 \\
\hline Imposição de familiares & 28 & 287 \\
\hline
\end{tabular}




\begin{tabular}{|l|l|l|}
\hline Influência de colegas que estudaram no IFFar & 67 & 248 \\
\hline
\end{tabular}

Fonte: Dados do perfil do estudante IFFar 2015

A análise das informações do quadro 2 nos permite identificar que a captura do jovem para a educação profissional passa a se produzir como oportunidade. E as políticas estão sendo gestadas no sentido de prover acesso para todos, cabendo ao sujeito empreender para aproveitar essa oportunidade.

A inclusão dos jovens na educação profissional através do ingresso na instituição mostra que esta é uma prática que leva em consideração a diversidade da juventude. Mas inclusão forma par com aprendizagem e, nesse sentido, para além de proporcionar o acesso, é preciso pensar como se dão os processos de aprendizagem a partir dessa oportunidade de ingresso.

Gestar políticas de acesso e não pensar nas práticas pedagógicas que ocorrem dentro das instituições é, no mínimo, promover aquilo que Veiga-Neto e Lopes (2011) nomeiam como in/exclusão. Essa expressão tem sido utilizada para dizer de espaços onde os sujeitos são subjetivados para ingressar, como espaços inclusivos, porém as práticas que ocorrem dentro desses espaços têm produzido a exclusão.

Assim, as estratégias de permanência constituem-se em processo de captura dos jovens para investimento e gerenciamento das suas próprias aprendizagens. No IFFar, um conjunto de políticas e programas é gestado para promover a permanência qualificada dos estudantes na educação profissional de nível médio, entre eles: programa permanência e êxito, programa de alimentação escolar, auxílios estudantis, recuperação paralela, programa de monitorias, projetos de ensino; e, uma rede de expertise constituída por diferentes profissionais (Assistente Social, Pedagogo, Psicólogo). Essas estratégias pedagógicas encontram-se descritas em todos os PPCs dos cursos técnicos integrados ${ }^{7}$, como pode ser observado a seguir: "[...] durante todo o itinerário formativo do aluno deverão ser previstas atividades de recuperação paralela, complementação de estudos, dentre outras atividades que o auxiliem a ter êxito na sua aprendizagem, evitando a não compreensão dos conteúdos, a reprovação e/ou evasão" (PPC do Curso Técnico Integrado em Agropecuária 2014, p. 39).

Capturar todos os jovens para a educação profissional opera no sentido de: capacitá-los, através de estratégias empregadas nos diferentes cursos; inseri-los nessa lógica de concorrência e produtividade, de aprendizagem permanente; e, oportunizá-los o desenvolvimento de competências e habilidades produzidas como importantes para a vida, para o trabalho e para participação nos processos produtivos.

Assim, a permanência com aprendizagem do jovem na educação profissional de nível médio pode ser relacionada à ideia de fluxo, empregada por Rech (2015), no sentido de que o jovem que ingressa na educação profissional corrobore com o fluxo de entrada e saída de jovens dessa

\footnotetext{
7 Todos os PPCs dos cursos técnicos integrados ao ensino médio do IFFar Campus Santo Augusto possuem os aspectos da organização e políticas de atendimento ao discente estruturados do mesmo modo, considerando que seguem a mesma legislação e orientação para elaboração.
} 
modalidade de educação, precisa ter se constituído constituindo-se sujeito com sujeito com condições de aprender constantemente e, ao mesmo tempo, desenvolvido habilidades e competências para progredir na escolarização.

Nessa lógica, pensando na não interrupção desse fluxo, é que na instituição são empregadas diferentes estratégias constituídas para que esse jovem, mesmo com diagnóstico de desvio na aprendizagem, seja capturado para construir suas aprendizagens, empreender sobre si e acompanhar esse movimento do fluxo.

\section{ESTRATÉGIAS DE INCLUSÃO E EMERGÊNCIA DE MODOS NORMALIZADORES PARA IDENTIFICAR ESTUDANTES E GESTAR O RISCO A NÃO APRENDIZAGEM}

No terceiro movimento, dois fios dessa complexa trama são considerados: um gira em torno de examinar como os discursos da inclusão e da aprendizagem tornam-se verdades que circulam no contexto do IFFar Campus Santo Augusto e atuam a partir de uma norma para identificar, classificar e gerenciar o risco de estudantes produzidos e nomeados em situação de não aprendizagem; e o outro, visa dar visibilidade analítica para as estratégias inclusivas institucionais, considerando que delas se apreendem processos educativos para pensar a permanência com aprendizagem de todos os jovens na educação profissional, e, para gestar o risco da não aprendizagem.

Para proceder com a análise, torna-se interessante as noções de norma e curva de normalidade, que, a partir dos currículos, determinam um perfil de aprendizagens e comportamentos a serem desenvolvido pelos estudantes. Assim, é possível mostrar como se aciona uma rede de saberes e estratégias de acesso e de permanência determinados por um perfil que é aceitável e que, por outro lado, constitui a margem, o desvio, a produção de um estudante em situação de não aprendizagem a ser incluído.

Entre os documentos explorados, que dizem das estratégias de inclusão no IFFar, estão: fichas de encaminhamento de estudantes; atas de conselho de classe; relatório de projetos de ensino; relatórios da Assistência Estudantil, e PPCs dos Cursos Técnicos Integrados ao Ensino Médio do IFFar Campus Santo Augusto.

Diante do exposto nos documentos, uma das atividades iniciais do ano letivo previstas nos PPCs dos cursos técnicos integrados do IFFar para todas as disciplinas, é a de nivelamento. Neste recorte do PPC do Curso Técnico Integrado em Administração, consta a definição de nivelamento como "[...] atividades de diagnóstico e revisão, com o objetivo de atender o nivelamento de saberes e conhecimentos, [...] no período inicial do ano letivo, tendo aproximadamente a duração de 30 dias letivos" (2014, p.18).

As atividades de nivelamento no início do ano letivo, vão dizer do nível do estudante e de como estão situados seus conhecimentos prévios para, só assim, entrarem no fluxo formativo. Cabe ao professor identificar e classificar em níveis de conhecimento ou níveis cognitivos estes estudantes.

Ao analisar dados do nivelamento do ano de 2017, uma turma de primeiro ano de um curso técnico integrado ao ensino médio do IFFar Campus Santo Augusto, na disciplina de matemática, o professor registra que o conhecimento de 'resolução de equações simples' é um conteúdo considerado 
básico para o estudante prosseguir nas aprendizagens matemáticas no ensino médio. Nesta turma com 35 estudantes, o professor identifica que $20 \%$ possuem conhecimentos adequados sobre esse conteúdo, $30 \%$ estão com pequena defasagem e 50\% estão com defasagem expressiva, com conhecimentos muito abaixo do esperado para o ano em curso.

Observa-se, portanto, nesses documentos, que, esquadrinhados, os estudantes são classificados entre: os que detêm o conhecimento matemático prévio para novas aprendizagens, bem como as características esperadas para o primeiro ano da educação profissional e; aqueles que não detêm os níveis de conhecimento esperados. Fato que corrobora para que os estudantes recebam algumas nomeações: competentes e (in)competentes. As referidas nomeações marcam os sujeitos normalizam e produzem posições de sujeito dentro do grupo - as quais irão acompanhá-los ao longo da estada no ensino médio na educação profissional.

Os dados sobre nivelamento produzidos no IFFar Campus Santo Augusto, que fazem parte do acervo de documentos pedagógicos da instituição, são desenhados estatisticamente, pois a população de estudantes se constitui em objeto calculável em que é possível a atuação da norma como modelo a ser seguido. Essa norma que atua no corpo individual, diz da noção de normal que o estudante deve, indispensavelmente, dominar dos conteúdos ao ingressar no primeiro ano do ensino médio. Assim, esses dados estatísticos, permitem estabelecer aquele que está na norma perfilada nos objetivos de aprendizagem dos cursos e, imediatamente, aquele que se desvia. Esta parece ser uma análise biométrica do sujeito para identificar onde ele se enquadra. Aprendemos com Foucault que,

[...] a operação de normalização vai consistir em fazer essas diferentes distribuições de normalidade funcionarem umas em relação às outras e [em] fazer de sorte que as mais desfavoráveis sejam trazidas às que são mais favoráveis. Temos, portanto, aqui uma coisa que parte do normal e que se serve de certas distribuições consideradas, digamos assim, mais normais que as outras, mais favoráveis em todo caso que as outras (2008, p. 83).

Nessa direção, Foucault (2008) afirma que existem duas formas de atuação da norma: uma por normação e outra por normalização. A primeira atua a partir da disciplina, como modelo a ser seguido, e a segunda atua a partir da população, regulando um modo de ser para todos que compõem o grupo.

Segundo Lopes (2009), Foucault (2008), Lockmann (2010), a norma é um dispositivo da governamentalidade. A norma é como um modelo a ser seguido, a partir do corpo individual, da disciplina, posicionando os sujeitos a partir de um processo de normação. Segundo Lockmann e Henning (2010, p. 192),

Para a norma, não existe exterioridade, nada escapa ao seu abrigo, ela captura a todos. Não há determinados sujeitos que se encontram fora do abrigo da norma e outros que estão no seu interior. Todos os sujeitos, sejam eles normais ou anormais, estão na norma, são capturados por ela e, por meio dos saberes produzidos, são classificados, ordenados, comparados e distribuídos.

Nessa perspectiva, buscamos, ao longo do estudo, compreender a norma como atuando nas práticas educacionais no IFFar Campus SA. Sendo, portanto, aplicada sobre o indivíduo-estudante e 
sobre a população-grupo/turma. Tendo a função síncrona de controlar-disciplinar, controlar-regular e, por efeito, estabelecer a ordenação entre os aprendentes e os em situação de não aprendizagem.

Essas práticas que colocam em funcionamento o intento de conformar os sujeitos, segundo padrões prévios constituídos no próprio grupo ao qual tais sujeitos são incluídos, constitui-se mais "[...] como uma normação do que uma normalização" (FOUCAULT, 2008, p. 76), porque a normação age sobre os indivíduos a partir de um princípio de comparação, no sentido de aplicar sobre eles o mecanismo disciplinar para regular os comportamentos e controlar os identificados como desviantes.

A normalização, como elemento ampliador da normação, é entendida por Foucault no âmbito da biopolítica. Para o autor, "[...] a norma está em jogo no interior das normalidades diferenciais. $\mathrm{O}$ normal é que é primeiro, e a norma se deduz dele, ou é a partir desse estudo das normalidades que a norma se fixa e desempenha seu papel operatório" (FOUCAULT, 2008, p. 83). Dito de outro modo, a norma não tem um modelo universal fixado, ela é variável, por isso no caso da educação "[...] a norma é estabelecida por meio de um estudo das características do corpo coletivo, de uma população" (CORRÊA; LOCKMANN, 2015, p. 03).

Com um conjunto de normas de perfil do estudante, de nivelamento e objetivos formativos, é possível visualizar nos PPCs os cursos um conjunto de práticas e saberes que, como a norma, atuam para a definição de modos de aprendizagem, definição do que é importante aprender, e do que é essencial para a constituição deste jovem no ensino médio integrado. Essas características não fazem parte simplesmente dos planos de atuação de um curso, mas se constituem nos princípios que compõem as reformas da educação profissional no Brasil. Essas reformas são parte da gestão da população e ampliam a segurança do Estado e no Estado, uma economia política em que a população é tanto alvo como instrumento em uma relação de poder. Como afirma Veiga-Neto,

[...] ao fazer de um desconhecido um conhecido anormal, a norma faz desse anormal mais um caso seu. Dessa forma, também o anormal está na norma, está sob a norma, ao seu abrigo. O anormal é mais um caso, sempre previsto pela norma. Ainda que o anormal se oponha ao normal, ambos estão na norma. É também isso que faz dela um operador tão central para o governo dos outros; ninguém escapa dela. (2011, p. 115, grifos nossos).

Nessa lógica, os estudantes, estando sob constante atuação da norma, são identificados como no eixo da norma ou como distantes do centro da norma. Alguns mais, outros menos. Entretanto, aqueles identificados como afastados do centro da norma passam a ser narrados como desviantes, e, ao se fazer isso, "[...] chama-se de anormal aquele cuja diferença em relação à maioria se convencionou ser excessivo, insuportável. Tal diferença passa a ser considerada um desvio, isso é, algo indesejável porque desvia" (VEIGA- NETO, 2014, p. 75), o que coloca o próprio sujeito em risco, assim como a própria instituição.

Com uma representação do risco da não aprendizagem, a instituição, pode então, gerenciar os riscos. Práticas que vão atuando sobre o sujeito através de diferentes estratégias com vistas a aproximá-lo ao máximo do eixo, do centro da norma, com intuito de "[...] reduzir as normalidades mais desfavoráveis, mais desviantes em relação à curva normal geral” (FOUCAULT, 2008, p. 82). 
Assim, os estudantes identificados com desvio na aprendizagem passam a serem alvos de algumas estratégias específicas com a intenção de direcioná-los para "[...] retomar aspectos nos quais os objetivos de aprendizagem não tenham sido atingidos" (PPC do Curso Técnico Integrado em Alimentos, 2014, p. 39).

É nesse contexto que se insere o trabalho de uma rede de expertise, identificada no PPC de cada curso como apoio psicopedagógico, conforme descrito a seguir: "O IFFar Campus SA possui uma equipe de profissionais voltada ao atendimento psicopedagógico dos estudantes, tais como: psicólogo, pedagogo, assistente social, técnico em assuntos educacionais e assistente de aluno" (PPC do Curso Técnico Integrado em Alimentos, 2014, p.19). Esses profissionais atuam estrategicamente a fim de municiar os estudantes para itingirem êxito em suas aprendizagens, e para ajustar a gestão dos fluxos de modo que os objetivos e o perfil de estudante traçados pela instituição logrem êxito.

No contexto de aprendizagem e inclusão, o serviço de apoio pedagógico ao discente, como parte da rede de expertise, atua diretamente para promover a aprendizagem dos estudantes que apresentam riscos diante das rotas traçadas para sua formação e, consequentemente, para sua permanência na instituição. Os passos para esta identificação começam pelo professor que se utiliza de critérios naturalizados nos planos institucionais. Esta avaliação inicial, coloca o estudante no fluxo das estratégias de recuperação, encaminhamentos, atendimentos, acompanhamentos, todos com o objetivo de: reestabelecer a rota de aprendizagem; aprender a empreender sobre suas aprendizagens; aprender a aprender e investir sobre si para, só assim, dar continuidade no curso.

Gestão do fluxo e aprendizagem se relacionam no sentido de que era preciso que o sujeito que está em um determinado curso, construa aprendizagens consideradas necessárias para progredir e movimentar esse fluxo de entrada e de saída de jovens do curso. Dito de outro modo, o sujeito ingressa, é conduzido por um processo de formação que diz aonde esse sujeito deve chegar e, reunidos os requisitos definidos como necessários, vai conseguir concluir o curso.

Aquele que não aprende dentro dos parâmetros utilizados e naturalizados, passa a ser tomado como um risco para o fluxo. Acaba por segurar a roda e, portanto, o investimento institucional na gestão dos fluxos que precisa que um estudante conclua para que outro ingresse. Investimento que dita que todos precisam aprender, ser aprovados e concluir seus cursos, para que só assim o fluxo perdure. Fato que corrobora para que existam vários investimentos que visem diminuir o percentual de desistência e evasão.

\section{CONSIDERAÇÕES FINAIS}

Para encerrar, salientamos que o exercício realizado neste artigo, foi uma experiência metodológica que nos pareceu proveitosa para compreender como as orientações de documentos internacionais constroem determinadas condições de possibilidade para a reforma na educação profissional e criação dos Institutos Federais no Brasil, as estratégias que operam como modo de captura dos jovens para a educação profissional, a emergência dos discursos da inclusão e a aprendizagem como discursos úteis para gestão da aprendizagem e a permanência do estudante na educação profissional. 
Além disso, este estudo nos mostrou que é possível compreender que a aprendizagem e a inclusão de todos são elementos que conduzem as políticas, as reformas educacionais no Brasil. Estes elementos constituem-se em verdade inquestionável que se estabelece em nossos dias e que nos inclina, como pontua Foucault, "[...] se é verdade, portanto, eu me inclino" (FOUCAULT, 2010, p. 71). Logo, conduz cada sujeito a conduzir suas condutas e suas relações com o outro a partir de um determinado regime de verdade. Assim, a inclusão constitui-se como uma verdade do nosso tempo, uma regra que diz como o jogo deve ser jogado e que captura a todos para jogar esse jogo.

Foi também possível entender a inclusão como uma estratégia da governamentalidade que age sobre cada indivíduo em particular, para atingir seu principal objetivo, o governo da população. Reiteramos ao longo da escrita que ao moldar as condutas, ao regular a forma de se produzir enquanto sujeito aprendente, ao normalizar a forma de aprender, ser e agir dos jovens, tem-se a intenção de produzir sujeitos que não constituam ameaça para a população, que não representem risco, mas busca-se produzir sujeitos produtivos que corroborem com a preservação da ordem social e a manutenção da seguridade da população.

É este movimento empreendido que desejamos compartilhar, e que possa ser tomado como um fio que, ao ser puxado, mexe com tramas estruturadas, estabilizadas. Com vistas a movimentar pensamentos, abalar algumas convicções que já estão consolidadas nessa trama desafiadora que é a inclusão e a educação profissional. Que este puxar de fios empreendido, possa provocar outros desfiares e mais problematizações sobre essa trama sejam produzidas.

\section{REFERÊNCIAS}

1. BANCO MUNDIAL. Aprendizagem para Todos Investir nos Conhecimentos e Competências das Pessoas para Promover o Desenvolvimento. 2011. Disponível em: <http://siteresources.worldbank.org/EDUCATION/Resources/ESSU/4632921306181142935/Portguese_Exec_Summary_ESS2020_FINAL.pdf>. Acesso em: 12 out 2016.

2. BID. Estratégias do Banco Interamericano para o Desenvolvimento do Brasil entre os anos $2000 \mathrm{e}$ 2003. Banco Interamericano para o Desenvolvimento, 2000.

3. BRASIL. SETEC/MEC. Um novo modelo em educação profissional e tecnológica. Concepção e Diretrizes. 2010.2 Disponível em: < http://portal.mec.gov.br/index.php?option=com_docman\&view=download\&alias=6691-ifconcepcaoediretrizes\&category_slug=setembro-2010-pdf\& Itemid=30192>. Acesso em janeiro de 2016.

4. BRASIL. SETEC/MEC. Lei $n^{0} 11.892$, de 29 de dezembro de 2008. Institui a Rede Federal de Educação Profissional, Científica e Tecnológica, cria os Institutos Federais de Educação, Ciência e 
Tecnologia, e dá outras providências. Diário Oficial da União, Brasília, DF, 2008. Disponível em: <http://www.planalto.gov.br/ccivil_03/_ato2007-2010/2008/lei//11892.htm>. Acesso em: 11 maio 2016.

5. BRASIL. SETEC/MEC. Plano de Desenvolvimento Institucional 2014-2018. Instituto Federal Farroupilha. Santa Maria, 2014.

6. BRASIL. SETEC/MEC. O plano de desenvolvimento da Educação: razão, princípios e programas. 2007. Disponível em: <http://portal.mec.gov.br/arquivos/livro/livro.pdf>. Acesso em: 05 de abr. 2016.

7. BRASIL. SETEC/MEC Projetos Pedagógicos de Cursos Técnicos Integrados ao Ensino Médio. Instituto Federal Farroupilha. 2014.

8. CORREA, Camila B. CAETANO, Letícia F. LOCKMANN, Kamila. Os discursos pró- inclusivos como estratégias de governamento que operam sobre docentes e discentes do ensino fundamental. In: XI Reunião Científica Regional da ANPED: Educação movimentos sociais e políticas governamentais. Curitiba/PR, 2016. Disponível em: http://www.anpedsul2016.ufpr.br/trabalhoscompletos-eixo-10-ensino-fundamental/

9. FOUCAULT, M. Segurança, território, população. São Paulo: Martins Fontes, 2008.

10. FOUCAULT, M. A ordem do discurso. São Paulo: Edições Loyola, 2010.

11. GATTERMANN, Beatris. Inclusão no IF Farroupilha Campus Santo Augusto: Conjunto de Práticas Políticas que tem Produzido Sujeitos. 2017. 150 p. Dissertação (Mestrado em Educação) Universidade Federal de Santa Maria, Santa Maria, RS. 2017.

12. GOUVEIA, K. R. As implicações da reforma da educação profissional brasileira na década de 90 na Escola Agrotécnica Federal de Barreiros - PE. 2005. 182 p. Dissertação (Mestrado em Educação) - Universidade Federal de Pernambuco, Recife, PE, 2005.

13. LOCKMANN, K. Inclusão Escolar: saberes que operam para governar a população. 2010. 180 p. Dissertação (Mestrado em Educação) - Universidade Federal do Rio Grande do Sul, Porto Alegre, RS, 2010.

14. LOCKMANN, K. A proliferação das políticas de assistência social na educação escolarizada: estratégias da governamentalidade neoliberal. 2013. 318 p. Tese (Doutorado em Educação) Universidade Federal do Rio Grande do Sul, Porto Alegre, RS, 2013. 
LOCKMANN, K. HENNING. P. C. Inclusão escolar na atualidade: um dispositivo da governamentalidade neoliberal. In: Revista de Educação PUC-Campinas. n.29, p.189-198, jul./dez., Campinas, 2010.

LOPES, M. C. Políticas de inclusão e governamentalidade. Revista Educação \& Realidade, 34(2), mai/ago 2009, p. 153-169.

17. MENDES, Enicéia Gonçalves. A radicalização do debate sobre inclusão escolar no Brasil. Revista Brasileira de Educação v. 11 n. 33, set./dez. 2006, p. 387-405.

18. OCDE. Panorama Educativo: Indicadores OCDE, 2003. Disponível em: <https://www.oecd.org/edu/skills-beyond-school/29880740.pdf>. Acesso em: 18 maio 2017.

19. RECH, T. L. Da escola à empresa educadora: a inclusão como uma estratégia de fluxo-habilidade. 2015. 259 p. Tese (Doutorado em Educação) - Universidade Federal do Rio Grande do Sul, Porto Alegre, RS, 2015.

20. SAURA, G. Neoliberalismo como discurso. La evaluación en educación entre tecnologías políticas neoliberales y la nueva filantropía. Revista Educação, Sociedade \& Culturas, n. 47, 2016, p. 11-30.

21. UNESCO. Declaração Mundial sobre Educação para Todos: satisfação das necessidades básicas de aprendizagem. Jomtiem: UNESCO, $1990 . \quad$ Disponível em: <http://unesdoc.unesco.org/images/0008/000862/086291por.pdf>. Acesso em: 25 ago 2017.

22. UNESCO. Organização das Nações Unidas para a Educação, a Ciência e a Cultura. Declaração de Incheon educação 2030: rumo a uma educação de qualidade inclusiva e equitativa e à educação ao longo da vida para todos. Unesco, 2015. Disponível em: <http://unesdoc.unesco.org/images/0023/002331/233137POR.pdf>. Acesso em: 19 abril. 2017.

23. VEIGA-NETO, A. Governamentalidade, neoliberalismo e educação. In. VEIGA-NETO, A.; BRANCO, G. C. Foucault: filosofia \& política. Belo Horizonte: Autêntica Editora, 2011.

24. VEIGA-NETO, A. Foucault e a Educação. Belo Horizonte: Autêntica, 2014.

25. VEIGA-NETO, A.; LOPES, M. C. Inclusão, exclusão, in/exclusão. In. Revista Verve, n. 20. p 121135, 2011.

\section{Beatris Gattermann}


Professora do Instituto Federal Farroupilha Campus Santo Augusto - RS. Mestre em Educação pela Universidade Federal de Santa Maria - UFSM.

\section{Leandra Boer Possa}

Doutora em Educação, com Estágio Pós-Doutoral em Políticas Públicas de Educação e Educação Comparada/bolsa CAPES. Professora Adjunta do Programa de Pós-Graduação em Educação e do Programa de Pós-Graduação em Políticas Públicas e Gestão Educacional Universidade Federal de Santa Maria.

Como citar este documento:

GATTERMANN, Beatris; POSSA, Leandra Boer. O PROCESSO DE INCLUSÃO ENQUANTO POLÍTICA PARA A EDUCAÇÃO PROFISSIONAL BRASILEIRA. Reflexão e Ação, Santa Cruz do Sul, v. 29 , n. 1, p. 169-186, jan. 2021. ISSN 1982-9949. Acesso em: doi: http://dx.doi.org/10.17058/rea.v29i1.12393 